\title{
Intrapartum Process
}

National Cancer Institute

\section{Source}

National Cancer Institute. Intrapartum Process. NCI Thesaurus. Code C92819.

The process that occurs during labor and delivery. 